\title{
Structure, Mechanical, Thermal and Fire Behavior Assessments of Environmentally Friendly Crude Glycerol-Based Rigid Polyisocyanurate Foams
}

\author{
Aleksander Hejna ${ }^{1}\left({ }^{10} \cdot\right.$ Paulina Kosmela $^{1} \cdot$ Mikelis Kirpluks $^{2} \cdot$ Ugis Cabulis $^{2}$ • \\ Marek Klein $^{3} \cdot$ Józef Haponiuk ${ }^{1} \cdot$ Lukasz Piszczyk $^{1}$
}

Published online: 27 July 2017

(C) The Author(s) 2017. This article is an open access publication

\begin{abstract}
In this work, rigid polyisocyanurate foams were prepared at partial substitution $(0-70 \mathrm{wt} \%)$ of commercially available petrochemical polyol, with previously synthesized biopolyol based on crude glycerol and castor oil. Influence of the biopolyol content on morphology, chemical structure, static and dynamic mechanical properties, thermal insulation properties, thermal stability and flammability was investigated. Incorporation of $35 \mathrm{wt} \%$ of crude glycerol-based polyol had reduced average cell size by more than $30 \%$ and slightly increased closed cell content, simultaneously reducing thermal conductivity coefficient of foam by $12 \%$ and inhibiting their thermal aging. Applied
\end{abstract}

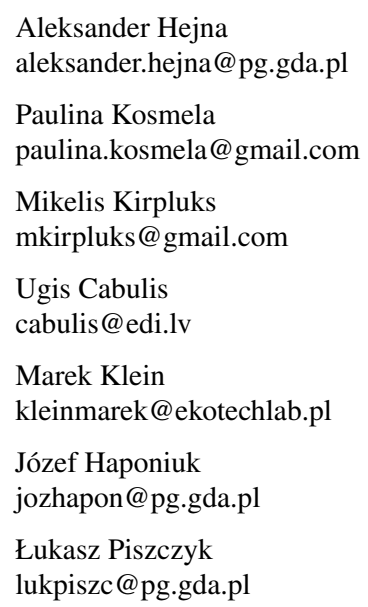

1 Present Address: Department of Polymer Technology, Chemical Faculty, Gdańsk University of Technology, G. Narutowicza Str. 11/12, 80-233 Gdańsk, Poland

2 Latvian State Institute of Wood Chemistry, 27 Dzerbenes, Riga 1006, Latvia

3 Renewable Energy Department, The Szewalski Institute of Fluid-Flow Machinery, Polish Academy of Sciences, Fiszera 14, 80-231 Gdańsk, Poland modifications showed also positive impact on the mechanical performance of rigid foams. Increase of crosslink density resulted in enhancement of compressive strength by more than 100\%. Incorporation of prepared biopolyol resulted in enhancement of thermal stability and changes in degradation pathway. Up to $35 \mathrm{wt} \%$ share of crude glycerol-based polyol, foams showed similar flammability as reference sample, which can be considered very beneficial from the environmental point of view.

Keywords Crude glycerol $\cdot$ Biopolyol $\cdot$ Rigid polyisocyanurate foams $\cdot$ Thermal properties $\cdot$ Thermal conductivity

\section{Introduction}

Nowadays, production of polyurethane (PU) materials is strictly bound to the petroleum industry, since majority of polyols used for PU manufacturing are petroleum-based. Although, ongoing trends related to sustainable development and environmental protection, together with nonrenewable character and unstable price of petroleum, are stimulating the incorporation of compounds from various renewable sources into production of polyols and PU materials [1]. As a result, over the last years many research groups became focused on environmentally friendly manufacturing of bio-based polyols for PU materials, e.g. rigid foams used as thermal insulation. Many different compounds have been investigated, including rapeseed [2-4], sunflower [5], palm [6], soybean [7, 8], linseed [9] and other natural oils $[10,11]$. These oils can be modified in various ways in order to increase their reactivity and suitability for PU preparation. Oxidation [2], epoxidation [12, 13], hydroformylation [14], ozonolysis [15] or esterification 
[16] of oils were applied by various researchers. Modified natural oils were successfully incorporated into preparation of PU materials, however their disadvantage is that they are currently used in food industry. Therefore, by far more interesting seems application of waste materials from processing of renewable raw materials, which can enhance the economic aspect of many processes and provide new methods of their recycling. Among various waste components examined in manufacturing of polyols for PU foams' preparation, it is worth to mention crude glycerol, resulting from biodiesel production. It is a by-product, generated in high amounts, only in Europe almost 1 million tonnes of crude glycerol is generated annually according to literature data $[17,18]$. Glycerol in its pure form is commonly applied in production of petrochemical based polyols further used in PU manufacturing, such as Lupranol 3300 (BASF), Carpol® GP-6015 (Carpenter Co.), Multranol 3901 (Bayer Material Science) or Rokopol G700 (PCC Rokita Sp. z o.o.). Crude glycerol can be considered an interesting and economically efficient alternative, due to its low price. Moreover, adding value to crude glycerol could have very beneficial impact on the profitability of biodiesel production [19]. Various research groups investigated its application in synthesis of biopolyols [20-22]. Also, foamed PU materials obtained with such biopolyols were produced, however investigation of their properties was often very limited and consisted only of basic mechanical testing [23, 24]. More detailed analysis was performed by $\mathrm{Li}$ et al. [25], although it did not include the evaluation of crude glycerolbased polyol's content in polyol mixture. Moreover, despite the fact that rigid PU foams are used mainly for thermal insulation, hardly any information can be found in the literature regarding the influence of crude glycerol-based polyols on thermal conductivity of rigid PU foams.

In previously presented studies [26] commercially available (Eco Innova) biopolyols based on crude glycerol were used in rigid PU foams' manufacturing. Incorporation of up to $35 \mathrm{wt} \%$ of biopolyol into rigid foam did not affect the performance of material and cellular structure. Hardly any changes in morphology, closed cell content and thermal conductivity coefficient were observed. However, at higher content, unfavorable effects were observed, resulting from disruption of cellular structure of foam.

Having in mind ongoing trends and changes in law regulations, it is important to develop thermal insulation materials, which are not only bio-based, but which can also meet the sharpening requirements for materials used in building industry. Such approach is emphasized in European Union, e.g. by Thermal insulation-green public procurement product sheet [27]. In case of rigid PU foams, enhancement of thermal stability and reduction of flammability can be achieved either by incorporation of appropriate modifiers or by adjustment of recipe in order to generate isocyanurate rings and prepare polyisocyanurate (PIR) foam. In presented research work we aimed to evaluate the influence of partial substitution of conventional, petrochemical polyol with crude glycerol-based biopolyol on performance of rigid PIR foams. Bio-based polyol was synthesized from crude glycerol and castor oil according to patent application developed at Department of Polymer Technology of Gdańsk University of Technology [28]. Its content in polyol mixture was altered from 0 to $70 \mathrm{wt} \%$. Chemical (FTIR studies) and cellular (SEM analysis, determination of closed cell content) structure, mechanical (compression tests, dynamic mechanical analysis) and thermal (thermogravimetric analysis, thermal conductivity coefficient measurement) properties and fire behavior of resulting rigid foams were examined.

\section{Experimental}

\section{Materials}

Castor oil and crude glycerol were used to prepare biobased polyol, called CG, used in this study. Castor oil was obtained from Pro-Lab (Poland), its hydroxyl value equaled $165 \mathrm{mg} \mathrm{KOH} / \mathrm{g}$, while its iodine value was in the range of $83-88 \mathrm{~g} \mathrm{I}_{2} / 100 \mathrm{~g}$. Crude glycerol was acquired from BioChem Sp. z o.o. (Poland), it contained 83 wt $\%$ of glycerol, $6 \mathrm{wt} \%$ of water, $6 \mathrm{wt} \%$ of soaps, $4 \mathrm{wt} \%$ of matter organic non-glycerol and less than $0.2 \mathrm{wt} \%$ of residual methanol. Moreover, during synthesis $85 \%$ aqueous solution of ortophosphoric (V) acid was used as a catalyst and 50\% aqueous solution of sulfuric (VI) acid was used to neutralize reaction products. Both these compounds were acquired from POCH S.A. (Poland). Crude glycerol used in this study was characterized by hydroxyl value of $525 \pm 28 \mathrm{mg}$ $\mathrm{KOH} / \mathrm{g}$.

Synthesized CG biopolyol was subsequently used to prepare rigid PIR foams, together with commercially available polyols from BASF company - Lupranol 3422 (high functional polyether based on sorbitol) and Lupranol 3300 (trifunctional polyether based on glycerol). Combination of two petrochemical polyols was used in order to combine their advantages. High crosslink density was achieved due to the application of high functionality Lupranol 3422. Lupranol 3300 was selected due to its low viscosity, which facilitated processing of polyurethane system containing very viscous Lupranol 3422. Combination of these two polyols was successfully applied in other research works [29, 30]. Properties of all polyols used in this study are summarized in Table 1.

Isocyanate used in the reaction was polymeric 4,4'-methylene diphenyl diisocyanate (pMDI) characterized by a 
Table 1 Properties of polyols used for the production of rigid PIR foams

\begin{tabular}{llll}
\hline Property & \multicolumn{2}{l}{ Polyol } \\
\cline { 2 - 4 } & CG & Lupranol 3300 & Lupranol 3422 \\
\hline Density (g/cm ${ }^{3}$ ) & 1.18 & 1.05 & 1.09 \\
$\begin{array}{l}\text { Hydroxyl number (mg } \\
\text { KOH/g) }\end{array}$ & 460 & 400 & 490 \\
Viscosity (mPa s) & 840 & 373 & 22,750 \\
Water content (wt\%) & 0.207 & 0.368 & 0.301 \\
\hline
\end{tabular}

$31.5 \%$ content of NCO groups (BASF). The average functionality of pMDI was c.a. 2.8 .

Tris(1-chloro-2-propyl)phosphate (TCPP) produced by LANXESS Deutschland GmbH (Levagard PP-technical name) was used as flame retardant. Potassium acetate (PC CAT ${ }^{\circledR}$ TKA30) and tertiary amine (PC CAT® NP-10) produced by Performance Chemicals were used as catalysts. Niax Silicone (L-6915) produced by Momentive Performance Materials Inc. was used as a stabilizer of porous structure. Distilled water and liquid hydrofluorocarbon blend (Solkane ${ }^{\circledR}$ 365/227) were used as a chemical and physical foaming agent, respectively.

\section{Synthesis of Bio-Based Polyol}

As mentioned before CG biopolyol was synthesized according to patent application developed at the Department of Polymer Technology of Gdańsk University of Technology [28]. Synthesis was two-step process, which consisted of crude glycerol polymerization and further reaction of obtained polyglycerol with castor oil, in order to decrease the hydroxyl value and viscosity of final product. Because of the very high content of ricinoleic acid castor oil was found to be an excellent modifier for condensed glycerol (main fatty acid components of castor oil are shown in the Fig. 1). Ricinoleic acid has in its structure both carboxyl and hydroxyl groups, thus its reaction with condensed glycerol, results in the decrease of the hydroxyl value (reduction of the density of hydroxyl groups), without the reduction of functionality, which is important for rigid polyisocyanurate foams. Additionally, according to Ionescu and Petrovic [24], neat polyglycerols are incompatible with aromatic isocyanates, such as pMDI used in this study, which is another reason for modification of condensed glycerol. Parameters of the reaction were based on literature studies of previous works and results of our own research [31, 32].

Properties of obtained biopolyol CG are presented in Table 2 and compared to condensed glycerol obtained after first step of the process. It can be seen that modification of condensed glycerol was justifiable. Generally, procedure of biopolyol preparation, together with its properties, was described in our previous work [33].

\section{Polyisocyanurate Foam Preparation}

Rigid PIR foams were produced on a laboratory scale by a single step method from a two-component (A and B) system with the isocyanate index (which is the ratio of the equivalent amount of isocyanate used relative to the

Table 2 Properties of condensed glycerol and biopolyol CG

\begin{tabular}{llcc}
\hline Polyol & $\begin{array}{l}\text { Hydroxyl value } \\
(\mathrm{mg} \mathrm{KOH} / \mathrm{g})\end{array}$ & $\begin{array}{l}\text { Viscosity } \\
(\mathrm{mPa})\end{array}$ & $\begin{array}{l}\text { Water } \\
\text { content } \\
(\mathrm{wt} \%)\end{array}$ \\
\hline Biopolyol CG & 460 & 840 & $\leq 0.10$ \\
Condensed glycerol & 523 & 1562 & 0.20 \\
\hline
\end{tabular}

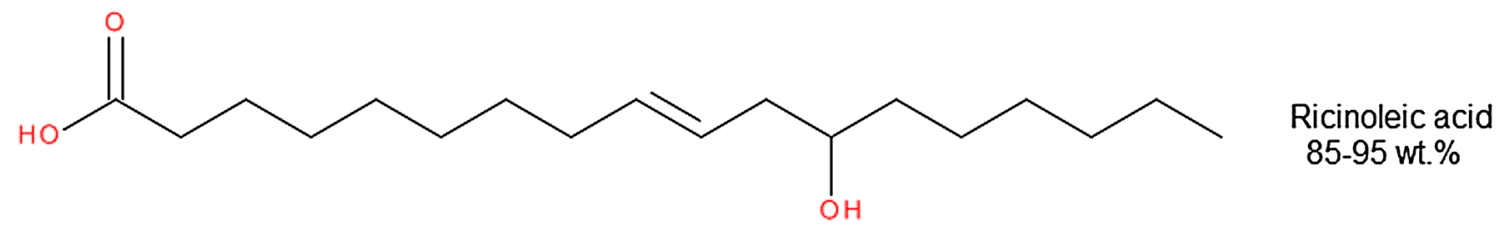<smiles>CCCCCCCCC=CCCCCCCCC(=O)O</smiles><smiles>CCCCC/C=C/C/C=C/CCCCCCCC(=O)O</smiles>

Fig. 1 Three main fatty acid components and their content in castor oil 
theoretical equivalent amount times 100) equal to 250 . High isocyanate index was used in order to generate isocyanurate rings in structure of foams, which are responsible for enhanced thermal stability and reduced flammability of rigid PIR foams in comparison to conventional PU foams. In the Fig. 2 there is presented general scheme of isocyanate trimerization responsible for generation of isocyanurate rings.

The component A (polyol mixture) consisting of the appropriate amounts of Lupranol 3422, bio-based polyol CG or their mixtures with Lupranol 3300 at various ratios, flame retardant, catalysts, surfactant and foaming agents was weighed and placed in a $500 \mathrm{~mL}$ polystyrene cup. Next, the polyol mixture was homogenized with a mechanical stirrer at $2000 \mathrm{rpm}$ for $20 \mathrm{~s}$. Such prepared component A was mixed with component B (pMDI) at a predetermined mass ratio and stirred at $2000 \mathrm{rpm}$ for $20 \mathrm{~s}$. The resulting reaction mixture was poured into an open mold of dimensions $100 \times 100 \times 50 \mathrm{~mm}$. Foams were cured for $24 \mathrm{~h}$ before demolding. After demolding, obtained samples were kept at $60{ }^{\circ} \mathrm{C}$ for $24 \mathrm{~h}$ and then conditioned at room temperature for $24 \mathrm{~h}$. Table 3 contains the details of foam formulations.

3

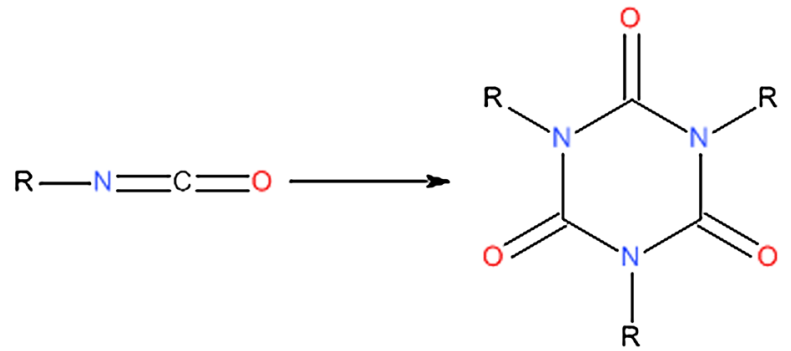

Fig. 2 Scheme of trimerization reaction resulting in generation of isocyanurate rings

Table 3 Formulations of prepared PIR foams

\section{Characterization}

Hydroxyl value of bio-based polyol was determined according to PN-93/C-89052/03. Samples of $0.5 \mathrm{~g}$ were placed in $250 \mathrm{~cm}^{3}$ Erlenmeyer flasks with acetylating mixture. Next, it was heated for $30 \mathrm{~min}$, then $1 \mathrm{ml}$ of pyridine and $50 \mathrm{ml}$ of distilled water were added. Finally, resulting mixture was titrated using $0.5 \mathrm{M} \mathrm{KOH}$ solution in presence of phenolphthalein until the color of mixture changed to pink. Hydroxyl values were determined according to formula (1):

$H V=\frac{56.1 \cdot\left(V_{K O H}^{2}-V_{K O H}^{1}\right) \cdot C_{K O H}}{m}$

where $\mathrm{C}_{\mathrm{KOH}}$ is the concentration of $\mathrm{KOH}, \mathrm{V}^{1}{ }_{\mathrm{KOH}}$ and $\mathrm{V}^{2}{ }_{\mathrm{KOH}}$ is the volume of $\mathrm{KOH}$ used to titration of analyzed sample and blind test, $\mathrm{m}$ is the mass of sample.

FT-IR spectrophotometric analysis was performed in order to determine the structure of rigid PIR foams. The analysis was performed at a resolution of $4 \mathrm{~cm}^{-1}$, at the range of wavenumbers from 4000 to $500 \mathrm{~cm}^{-1}$ (64 scans), using a Nicolet 8700 apparatus (Thermo Electron Corporation) equipped with a snap-Gold State II which allows for making measurements in the reflection configuration mode.

After curing, foams were cut into samples whose properties were later determined in accordance with the standard procedures. The apparent density of samples was calculated in accordance with EN ISO 845: 2000, as a ratio of the sample weight to the sample volume $\left(\mathrm{g} / \mathrm{cm}^{3}\right)$. The cylindrical samples were measured with a slide caliper with an accuracy of $0.01 \mathrm{~mm}$ and weighed using electronic analytical balance with an accuracy of $0.0001 \mathrm{~g}$.

Sol fraction was determined during swelling test. Samples of PU/PIR foams (around $0.2 \mathrm{~g}$ ) were swollen in xylene for $72 \mathrm{~h}$ (room temperature). Sol fraction was calculated as

\begin{tabular}{|c|c|c|c|c|c|c|}
\hline & & & & & & \\
\hline & & OCG & $17.5 \mathrm{CG}$ & $35 \mathrm{CG}$ & $52.5 \mathrm{CG}$ & $70 \mathrm{CG}$ \\
\hline & Lupranol 3422 & 30.0 & 30.0 & 30.0 & 30.0 & 30.0 \\
\hline & Lupranol 3300 & 70.0 & 52.5 & 35.0 & 17.5 & - \\
\hline & CG & - & 17.5 & 35.0 & 52.5 & 70 \\
\hline & TCPP & 25.0 & 25.0 & 25.0 & 25.0 & 25.0 \\
\hline & CAT NP-10 & 1.5 & 1.5 & 1.5 & 1.5 & 1.5 \\
\hline & CAT TKA30 & 1.5 & 1.5 & 1.5 & 1.5 & 1.5 \\
\hline & L-6915 & 2.0 & 2.0 & 2.0 & 2.0 & 2.0 \\
\hline & Solkane & 52.0 & 42.0 & 38.0 & 32.0 & 24.0 \\
\hline & Water & 0.5 & 0.5 & 0.5 & 0.5 & 0.5 \\
\hline & Isocyanate & 285.2 & 292.1 & 295.5 & 298.9 & 305.7 \\
\hline & Isocyanate index & 250 & 250 & 250 & 250 & 250 \\
\hline & Bio-polyol content in polyol mixture (wt\%) & 0 & 17.5 & 35.0 & 52.5 & 70.0 \\
\hline & Content of bio-polyol in foam (wt\%) & 0 & 3.8 & 7.5 & 11.4 & 15.2 \\
\hline
\end{tabular}


mass difference of biocomposites before swelling $\left(\mathrm{W}_{1}\right)$ and after extraction $\left(\mathrm{W}_{2}\right)$, according to Eq. (2):

Sol fraction $=\frac{\mathrm{W}_{1}-\mathrm{W}_{2}}{\mathrm{~W}_{1}} \times 100 \%$

The compressive strength of rigid foams was estimated in accordance with EN ISO 844:2007. The cylindrical samples with dimensions of $20 \times 20 \mathrm{~mm}$ (height and diameter) were measured with a slide caliper with an accuracy of $0.1 \mathrm{~mm}$. The compression test was performed on a Zwick/ Roell $1000 \mathrm{~N}$ testing machine at a constant speed of $10 \% /$ min until reaching $15 \%$ deformation.

A Tescan TS 5136 MM scanning electron microscope (SEM) with a secondary electron (SE) detector was used to take images of surface morphology. Before the SEM investigation, samples with a size of $10 \times 10 \times 2 \mathrm{~mm}$ were cut and sputtered with a gold layer using an Emitech K550X sputter coater (current $25 \mathrm{~mA}$, coating time $2 \mathrm{~min}$ ). Obtained data and images were processed with Vega TC software. Closed cell content of prepared rigid PIR foams was determined according to ISO 4590:2003.

Dynamic mechanical analysis was performed using DMA Q800 TA Instruments apparatus. Samples were analyzed in compression mode with a frequency of $1 \mathrm{~Hz}$. Measurements were performed for the temperature range from 25 to $270{ }^{\circ} \mathrm{C}$ with heating rate $4{ }^{\circ} \mathrm{C} / \mathrm{min}$. Samples were cylindrical-shaped with dimensions of $8 \times 12 \mathrm{~mm}$.

The thermal conductivity in the range between 0 and $20^{\circ} \mathrm{C}$ was tested with Linseis HFM (Heat Flow Meter) 200.

In order to evaluate the thermal stability of materials, thermogravimetric analysis (TGA) was performed on 5-mg samples by means of a Netzsch TG 209 apparatus under argon atmosphere in the temperature range from 100 to $600{ }^{\circ} \mathrm{C}$ and at a heating rate of $20^{\circ} \mathrm{C} / \mathrm{min}$.

The behavior of rigid PIR foams under heat flux of $35 \mathrm{~kW} / \mathrm{m}^{2}$ during $300 \mathrm{~s}$ was tested using FTT Dual Cone Calorimeter(Fire Testing Technology Ltd., UK). Tests were done according to ISO5660-1 standard. The following testing parameters were chosen: surface area $-88.4 \mathrm{~cm}^{2}$; separation-25 mm, orientation-horizontal. During the experiments, time required to initiate the reaction of combustion and thermokinetic parameters i.e. average heat release rate (HRR), total heat release (THR), total smoke released (TSR) are determined.

\section{Results and Discussion}

\section{Structure of Rigid PIR Foams}

In Table 4 there are presented properties of prepared rigid PIR foams. Apparent density has great impact on the performance of foamed materials, because it determines the share of solid material in particular volume. Formulations of foams were developed (varying amount of physical blowing agent Solkane 365/227) in order to provide the similar density for all investigated materials at the level of $45.5 \pm 2.0 \mathrm{~kg} / \mathrm{m}^{3}$. It can be seen (Table 3 ) that incorporation of CG biopolyol into polyol mixture decreased the amount of hydrofluorocarbon foaming agent necessary to provide similar level of volumetric expansion during manufacturing of foam, by more than $50 \%$, which can be considered very beneficial from the economic and technological point of view. Such phenomenon can be related to the residual lower molecular weight compounds, volatile in temperatures reached during manufacturing of rigid PIR foams. Due to the complexity of materials used to synthesize applied CG biopolyol, especially crude glycerol, such compounds can be present in biopolyol.

In Table 4 there are presented parameters describing cellular structure of investigated PIR foams, such as cell size, cell aspect ratio and cell roundness. All parameters were determined from SEM images of samples presented in the Fig. 3, using ImageJ computer software. In order to calculate shape descriptors software fitted ellipses into foams' cells and used the following formulas ( 3 and 4 ):

$$
\begin{aligned}
& A R=\frac{L_{l}}{L_{s}} \\
& R=4 \cdot \frac{A}{\pi \cdot L_{l}^{2}}
\end{aligned}
$$

where $L_{l}$ and $L_{s}$ mean the length of longer and shorter axis of fitted ellipse and $A$ is the area of ellipse.
Table 4 Comparison of foams' properties

\begin{tabular}{lccccc}
\hline Properties & \multicolumn{5}{l}{ Foam symbol } \\
\cline { 2 - 6 } & 0CG & $17.5 \mathrm{CG}$ & $35 \mathrm{CG}$ & $52.5 \mathrm{CG}$ & $70 \mathrm{CG}$ \\
\hline Apparent density $\left(\mathrm{kg} / \mathrm{m}^{3}\right)$ & $44.9 \pm 0.3$ & $43.6 \pm 1.2$ & $46.6 \pm 2.6$ & $47.0 \pm 1.1$ & $47.5 \pm 1.1$ \\
Average cell diameter $(\mu \mathrm{m})$ & $420 \pm 31$ & $332 \pm 24$ & $315 \pm 33$ & $277 \pm 26$ & $280 \pm 34$ \\
Cell aspect ratio & $1.6 \pm 0.3$ & $1.5 \pm 0.4$ & $1.7 \pm 0.5$ & $1.7 \pm 0.3$ & $1.7 \pm 0.6$ \\
Cell roundness & $0.7 \pm 0.1$ & $0.7 \pm 0.2$ & $0.6 \pm 0.2$ & $0.6 \pm 0.1$ & $0.6 \pm 0.2$ \\
Sol fraction $(\mathrm{wt} \%)$ & $6.2 \pm 0.9$ & $5.2 \pm 1.1$ & $4.8 \pm 0.8$ & $3.0 \pm 0.0$ & $2.7 \pm 0.2$ \\
\hline
\end{tabular}



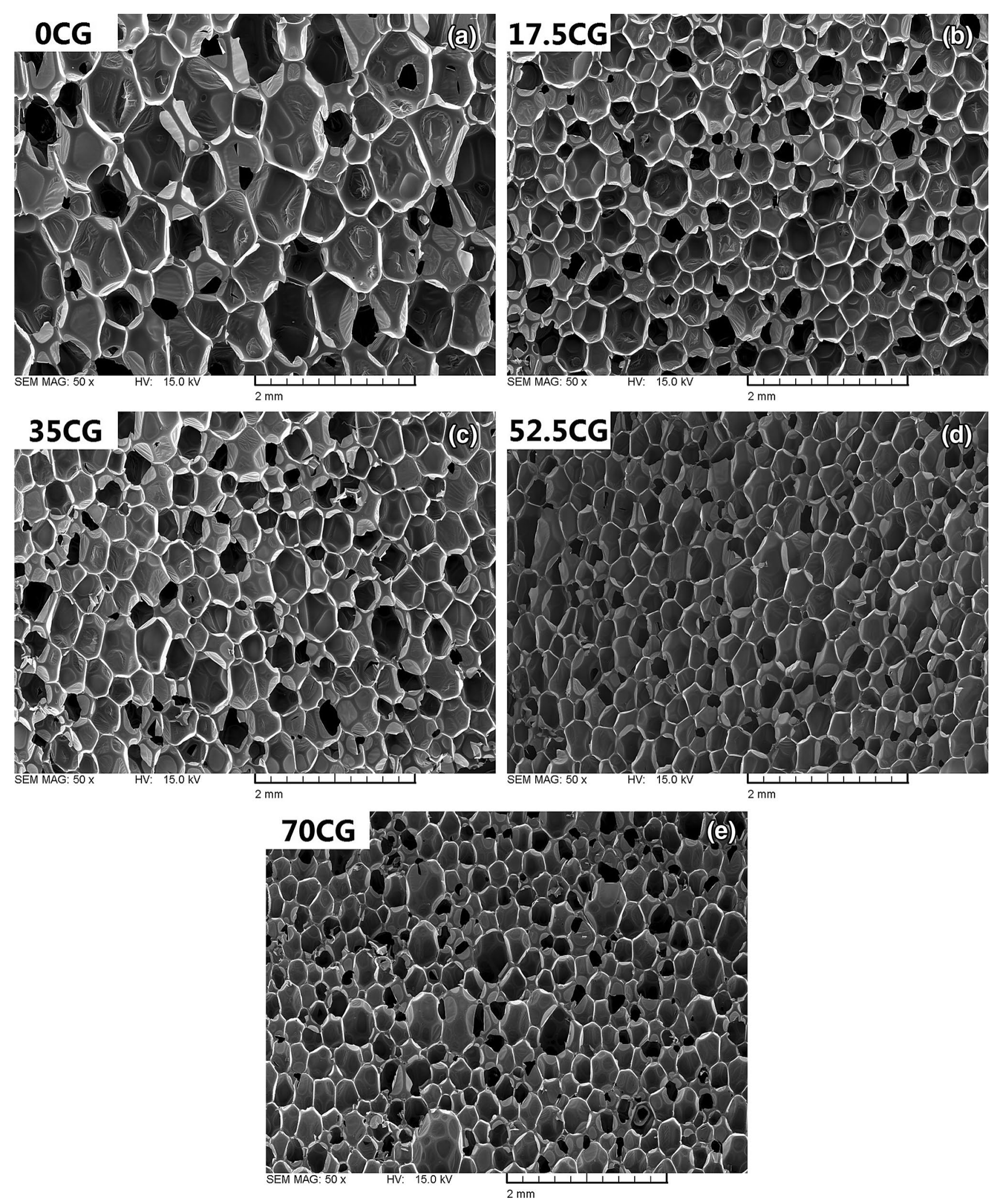

Fig. 3 SEM micrographs of foams containing 0, 17.5, 35, 52.5 and $70 \mathrm{wt} \%$ of CG biopolyol in polyol mixture 
Incorporation of up to $52.5 \mathrm{wt} \%$ of crude glycerol-based polyol into foams decreased average cell diameter from 420 to $277 \mu \mathrm{m}$, which can be also seen on SEM images presented in the Fig. 3. Complete substitution of Lupranol 3300 with CG biopolyol did not lead to further reduction of cell size, considering standard deviation, hardly any effect was observed.

For perfectly circular pores, values of $A R$ and $R$ are equal to one. Modification of foams resulted in small changes of cells' shape. Slight elongation of cells along the foaming direction was observed, which was associated with the accelerated evaporation of physical blowing agent during reaction. Such effect was related to the increased heat generation during polymerization, as a result of cross-link density increasing with the content of biopolyol. It was later confirmed by swelling test and FTIR analysis. Similar effect was observed by Zieleniewska et al. [34], when using rapeseed oil-based biopolyol. Anisotropy of the structure had also noticeable impact on the static and dynamic mechanical properties of obtained rigid PIR foams, which can be seen further.

In Table 4 there are also presented values of sol fraction of PIR foams determined during swelling test. As it can be seen, increasing share of CG biopolyol in polyol mixture resulted in decrease of sol fraction, which can be associated with the increased cross-link density, later confirmed by the FTIR analysis of foams. Such effect may be related to the higher hydroxyl value of CG biopolyol in comparison to Lupranol 3300, and hence, higher spatial density of urethane bonds in structure of analyzed materials.

The FTIR spectra of analyzed foams are presented in Fig. 4. Absorption band characteristic for stretching vibrations of $\mathrm{N}-\mathrm{H}$ groups (in urethane linkages) was observed in the range $3290-3320 \mathrm{~cm}^{-1}$. Bands attributed to the bending vibrations of these groups were observed at $1510-1520 \mathrm{~cm}^{-1}$ [35]. The absorption maxima at $1705-1715 \mathrm{~cm}^{-1}$ were corresponding to the stretching vibrations of $\mathrm{C}=\mathrm{O}$ bonds. Signals at $1200-1215 \mathrm{~cm}^{-1}$ can be associated with stretching vibrations of $\mathrm{C}-\mathrm{N}$ bonds in urethane linkages [36]. The aforementioned absorption bands confirm the presence of urethane bonds in the investigated material. In the Fig. 5 it can be seen that the magnitude of those peaks is increasing with the share of biopolyol in polyol mixture. It can be related to the increased cross-link density of material, confirmed by swelling tests, responsible for enhanced mechanical performance. The signals at $2860-2870$ and $2960-2975 \mathrm{~cm}^{-1}$ were attributed to the symmetric and asymmetric stretching vibrations of $\mathrm{C}-\mathrm{H}$ bonds in $\mathrm{CH}_{2}$ groups present in aliphatic chains and $\mathrm{CH}_{3}$ end groups. Low intensity peaks at $2260-2280 \mathrm{~cm}^{-1}$ resulted from the presence of unreacted $-\mathrm{N}=\mathrm{C}=\mathrm{O}$ groups, due to the excess of isocyanate used in the synthesis of foams [37]. Magnitude of these peaks is decreasing with



Fig. 4 FTIR spectra of prepared rigid PIR foams

the increasing share of biopolyol on behalf of previously mentioned peaks responsible for bonds present in urethane groups and peaks present at $1410-1415 \mathrm{~cm}^{-1}$, which were assigned to the presence of isocyanurate rings, products of the isocyanate trimerization [38]. Multiplet bands in the range of $1000-1090 \mathrm{~cm}^{-1}$ were associated with the presence of $\delta$ bonds between carbon and oxygen atoms (in the case of ether bonds), which is related to the structure of used polyols [39].

\section{Mechanical Properties of Rigid PIR Foams}

As mentioned before, apparent density has a great influence on the properties of foamed materials. During compression the stiffness of the material arises from buckling of cell walls and higher density is obviously related to the more compact cellular structure [40]. In the Fig. 6 there are presented values of compressive strength and modulus of investigated rigid PIR foams. It can be seen that incorporation of crude glycerol-based biopolyol resulted in the improvement of foams' mechanical strength, which can be associated with the increased cross-link density. Also stiffness of the structure was enhanced, which was later confirmed by the results of dynamic mechanical analysis. Compression tests were conducted in two directions, parallel and perpendicular to the direction of foam rise, in order to determine the effect of foams' structural anisotropy on their mechanical properties. Figure 6 shows that anisotropy of the cellular structure corresponds with the anisotropy in compressive performance of foams, which confirms the results presented by other researchers $[3,41]$.

In Table 5 and Figs. 7 and 8 there are presented results of dynamic mechanical analysis of prepared rigid PIR foams. It can be seen that storage modulus of foams $\left(E^{\prime}\right)$ is increasing with the share of CG biopolyol in foams, which confirmed results of compression tests. As mentioned before, 

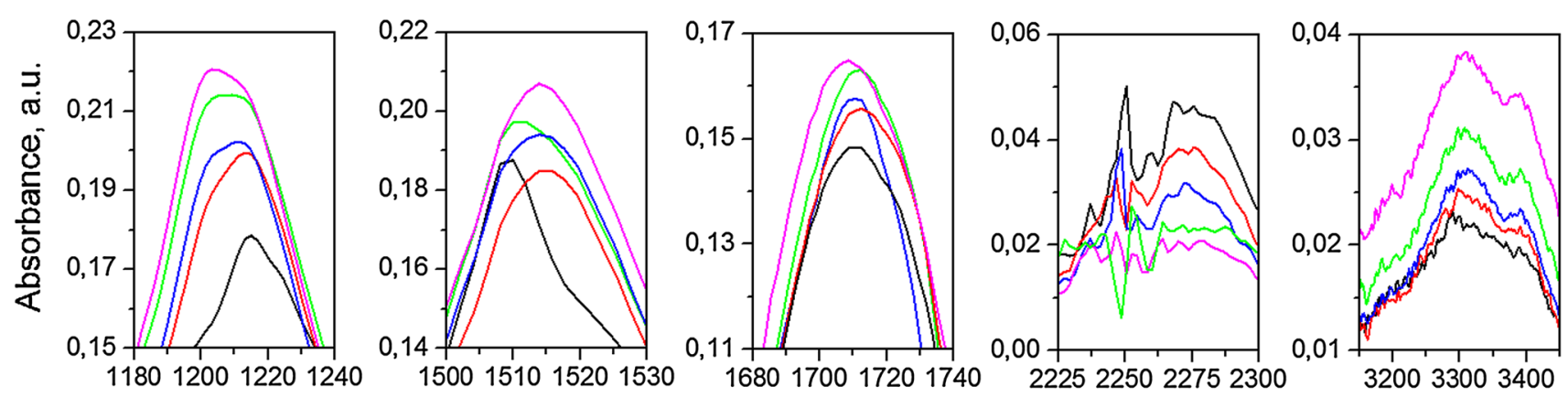

Wavenumber, $\mathrm{cm}^{-1}$

Fig. 5 Detailed FTIR spectra of investigated rigid PIR foams
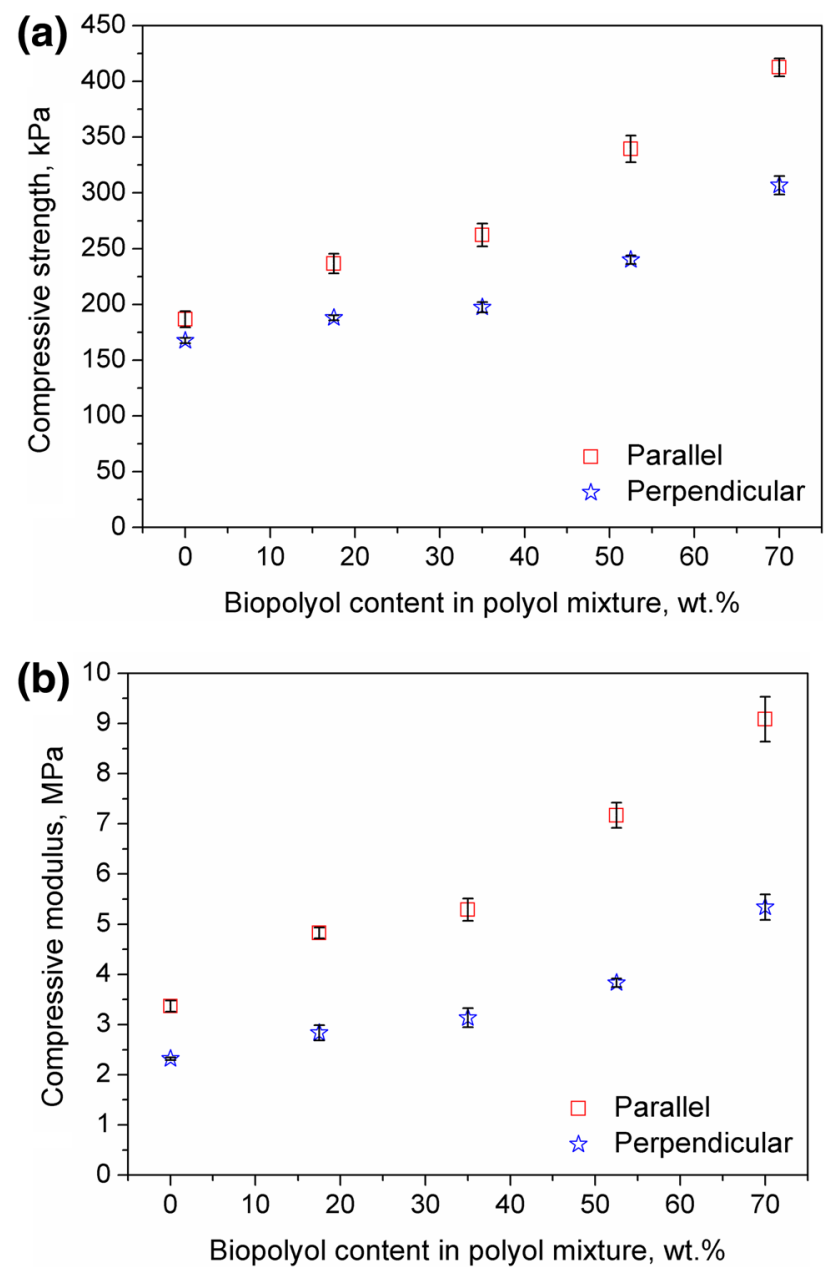

Fig. 6 Values of a compressive strength and $\mathbf{b}$ compressive modulus of prepared rigid PIR foams

such effect is associated with the increase of cross-link density with share of CG biopolyol in polyol mixture, which hindered the molecular motion [42]. The highest values of $\mathrm{E}^{\prime}$ were observed for sample containing only petrochemical
Table 5 Results of dynamic mechanical analysis of prepared PIR foams

\begin{tabular}{lllll}
\hline Sample & $\begin{array}{l}\mathrm{E}^{\prime} \text { at } 25{ }^{\circ} \mathrm{C} \\
(\mathrm{MPa})\end{array}$ & $\begin{array}{l}\mathrm{E}^{\prime \prime} \text { at } 25{ }^{\circ} \mathrm{C} \\
(\mathrm{MPa})\end{array}$ & $\tan \delta$ at $25{ }^{\circ} \mathrm{C}$ & $\mathrm{T}_{\mathrm{g}}\left({ }^{\circ} \mathrm{C}\right)$ \\
\hline 0CG & 0.65 & 0.07 & 0.11 & 214.6 \\
17.5CG & 1.71 & 0.16 & 0.11 & 217.0 \\
35CG & 2.22 & 0.20 & 0.09 & 217.5 \\
$52.5 \mathrm{CG}$ & 3.39 & 0.27 & 0.08 & 221.1 \\
$70 \mathrm{CG}$ & 4.70 & 0.36 & 0.08 & 224.5 \\
\hline
\end{tabular}

polyols, which was characterized by higher value of sol fraction, suggesting lower cross-link density. As a result, strain inside the material was lower and $\mathrm{E}^{\prime}$ value was simultaneously higher. Slight rise of $\mathrm{E}^{\prime}$ value with temperature was observed below $120^{\circ} \mathrm{C}$. Such effect was related to the acceleration of atoms' movement with temperature, which increased the stress inside the material. Nevertheless, the polymer chains were frozen below glass transition temperature, resulting in an almost unchanged strain. Hence, storage modulus, which is directly proportional to stress and inversely proportional to strain, was increasing below $\mathrm{T}_{\mathrm{g}}$ [43]. The biggest rise of $\mathrm{E}^{\prime}$ was observed for sample $0 \mathrm{CG}$, which can be associated with the lowest cross-link density, hence higher mobility of polymer chains, even below $T_{g}$. Moreover, for foams characterized with higher cross-link density, the increase of modulus below $\mathrm{T}_{\mathrm{g}}$ was observed at higher temperatures, which is also related to molecular motions hindered by cross-links. When $\mathrm{T}_{\mathrm{g}}$ was reached and exceeded mobility of polymer chains increased and rapid drop of $\mathrm{E}^{\prime}$ value was observed.

Loss modulus $\left(\mathrm{E}^{\prime \prime}\right)$ is a measure of the energy lost due to the internal friction. It can be seen that the $\mathrm{E}^{\prime \prime}$ value increases with the temperature and reaches the maximum value around glass transition region, which is related to the mobility of molecular chains. Peaks observed on loss modulus curves were broadening with the increase of 

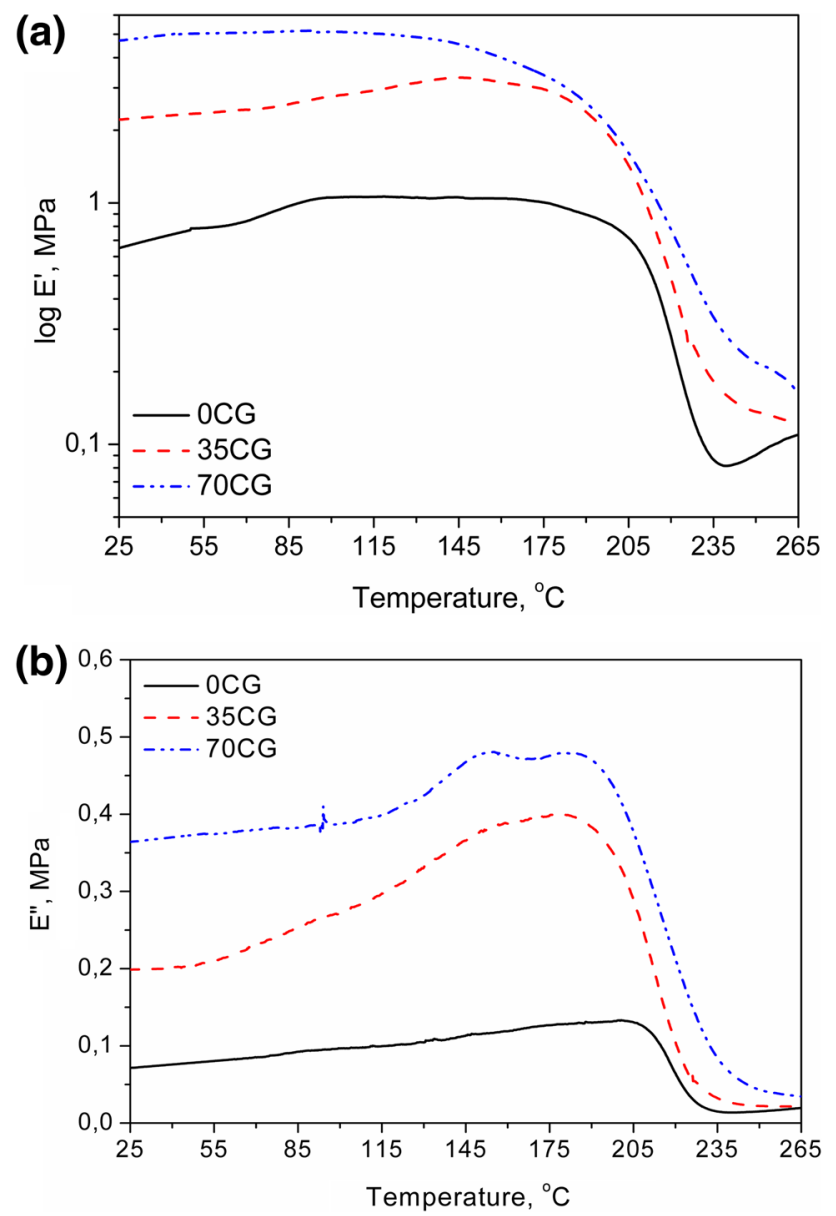

Fig. 7 Plots of a storage modulus and $\mathbf{b}$ loss modulus as a function of temperature for prepared rigid PIR foams

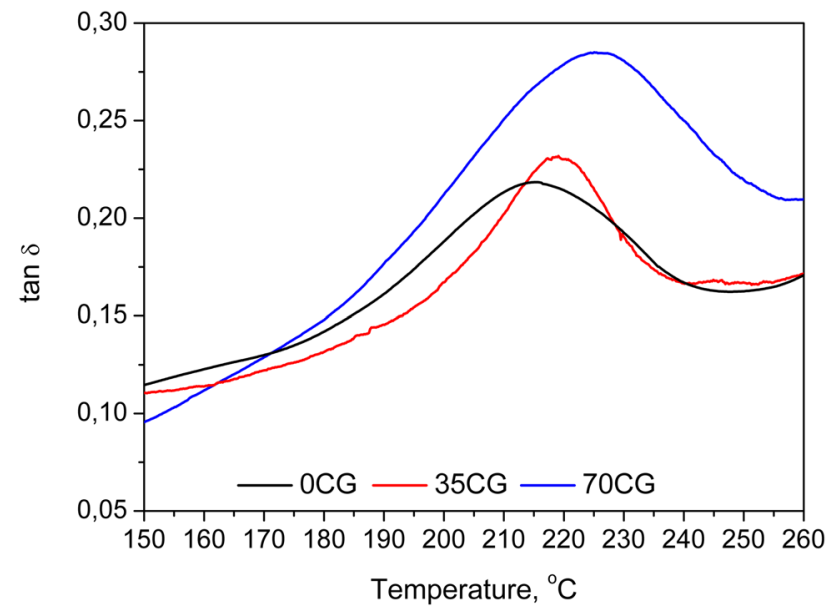

Fig. 8 Plot of loss tangent of rigid PIR foams as a function of temperature
CG polyol share. Such effect is related to the increasing heterogeneity of structure and molecular weights of polyol chains, due to the incorporation of biopolyol, whose structure is different than for Lupranol 3300. Used petrochemical polyol is polyether, while CG biopolyol contains in its structure also ester groups, which show different behavior, during DMA analysis [44]. Other important factor is increasing cross-link density of foams [45, 46].

Decreasing values of loss tangent are in line with the increasing cross-link density of analyzed PIR foams. The lower value of $\tan \delta$, the more elastic is the material, high values are typical for materials with a high, nonelastic strain component, which show enhanced possibility for energy dissipation by molecular motions [47]. In the Fig. 8 there are also presented plots of loss tangent $(\tan \delta$ ) of foams as function of temperature. Position of the peaks seen in the plot can be used to determine the glass transition temperature of material, which was presented in Table 5. It can be seen that the increasing share of biopolyol in polyol mixture resulted in the shift of $\mathrm{T}_{\mathrm{g}}$ towards higher temperatures, from $214.6{ }^{\circ} \mathrm{C}$ for sample 0CG to 217.5 and $224.5{ }^{\circ} \mathrm{C}$, respectively for 35CG and $70 \mathrm{CG}$ foams. Such effect can be related to the changing structure of polyol chains between crosslinks, increasing the amount of ester groups, which are present in CG biopolyol, in contrary to Lupranol 3300 , resulted in the shift of $\mathrm{T}_{\mathrm{g}}$. Obtained results are in line with the results of swelling test and values of loss tangent and storage modulus at ambient temperature. Similar results related to the incorporation of bio-based polyols into rigid PIR foams were observed at other works [48]. Authors related increasing $\mathrm{T}_{\mathrm{g}}$ to the flexibility of hydrocarbon chain of biopolyol lower than in case of petrochemical polyol, due to the increasing content of high order hydroxyl groups, which enhanced cross-link density of foams. In case of investigated materials values of $T_{g}$ can be affected, by thermal decomposition of foams starting slightly below glass transition temperature, however the relationship between $T_{g}$ value and CG biopolyol content is in line with the results of other performed analyses.

Nevertheless, it can be seen that investigated modification of foams not only shifts the temperature position of $\tan \delta$ peak, but also increases height of the peak, which can be associated with the nature of polymeric material and its ability to dissipate energy by internal friction and molecular motions. In contrary to the ambient temperature, at glass transition region increasing share of biopolyol is enhancing the magnitude of $\tan \delta$ peak, which can be related to structural changes of material, associated with thermal decomposition of foams containing $\mathrm{CG}$ biopolyol, starting at the range of $205-225^{\circ} \mathrm{C}$, which was concluded from TGA results. 


\section{Thermal Properties and Flammability of Rigid PIR Foams}

As mentioned before, rigid PIR foams are commonly used as thermal insulation materials. This application is very important from the energetic and environmental point of view. It is estimated that globally around $40 \%$ of energy is used for maintaining the proper temperature in rooms, either through heating, as well as air conditioning. It shows how important thermal insulation is in construction of buildings. One of the most important parameters of PIR foams, often determining their application, is thermal conductivity, which is strictly associated with the cellular structure of material. Thermal conductivity is expressed in the form of thermal conductivity coefficient, noted as $\lambda$, and consists of following elements: $\lambda_{\text {gas }}, \lambda_{\text {PIR }}, \lambda_{\text {radiation }}$ and $\lambda_{\text {convection }}$ [49]. Hence, it can be stated, that thermal conductivity coefficient strongly depend on the apparent density of foamed material, since it is associated with the share of gas and solid PU in total volume of material. Obviously, lower density increases the influence of $\lambda_{\text {gas }}$ on total $\lambda$ value and gases present in pores of the foam have lower thermal conductivity coefficient than solid PU, which can be seen in Table 6. As a result, foams with relatively low apparent density are most often used as thermal insulation materials. Moreover, high values of closed cell content are also beneficial for the insulation properties, because physical blowing agents or carbon dioxide generated during chemical foaming are then trapped into closed cells, while in case of open-cell structure exchange of these gases with air, possessing higher $\lambda$ value, occurs much faster.

Except the actual content of cells in total volume of foam, which is related to the density of the material, also properties of these cells are very important for the insulation properties of foam. According to Kurańska et al. [3] increase of cross section area of cells by $5 \%$ resulted in rise of $\lambda$ value by $5 \%$, at the same level of closed cell content. Randall and Lee noted 50\% increase of thermal conductivity coefficient for cell diameter increase from 0.25 to $0.60 \mathrm{~mm}$ [50]. Such a strong impact of cell size on $\lambda$ value is associated with one of its constituents $-\lambda_{\text {radiation }}$, which

Table 6 Values of thermal conductivity coefficients of foam constituents [50]

\begin{tabular}{lc}
\hline Constituent & $\begin{array}{l}\text { Thermal conductiv- } \\
\text { ity coefficient [mW/ } \\
(\mathrm{m} \mathrm{K})]\end{array}$ \\
\hline Solid PIR & 220.0 \\
Solkane 365/227 & 10.6 \\
Carbon dioxide & 15.3 \\
Air & 24.9 \\
\hline
\end{tabular}

can be mathematically expressed using following equations [51] (5 and 6):

$\lambda_{\text {radiation }}=\frac{16 \sigma T^{3}}{3 K}$

where:

$K=4.1 \cdot \frac{\sqrt{f_{s} \frac{\rho_{f}}{\rho_{p}}}}{d}$

where $\sigma$ is Stefan-Boltzmann constant and equals $5.67 \times 10^{-8} \mathrm{~W} / \mathrm{m}^{2} \mathrm{~K}^{4} ; T$ is temperature; $K$ means Rosseland mean extinction coefficient; $f_{S}$ is fraction of polymer in struts; $\rho_{f}$ and $\rho_{p}$ density of foam and polymer, respectively; and $d$ is cell diameter.

Basing of presented equations it is clear that the increase of cell size cause simultaneous increase of $\lambda_{\text {radiation }}$ and therefore increase of total $\lambda$ value of foam.

Other mechanism of heat transfer is convection. It is related to the displacement of substance in liquid or gaseous state as a result of gradient of temperatures in any volume. Convection can be also described by mathematical formula (7):

$q=h A \Delta T$

where $q$ is the heat transferred per unit time, $h$ is the heat transfer coefficient, $A$ is the area implied in the heat transfer process and $\Delta T$ is the difference in temperatures causing convection.

It can be seen that the heat convection is strongly related to the area through which convection occurs. Therefore, crucial parameter for this type of heat transfer in foams is content of closed cells. Their increasing content noticeably decreases area of convection, in case of high value of closed cell content conductivity through convection can be even omitted [52].

In the Fig. 9 there is shown the effect of prepared biopolyol content in polyol mixture on the closed cell content and thermal conductivity coefficients of resulting rigid PIR foams. Incorporation of CG biopolyol up to $52.5 \mathrm{wt} \%$ slightly increased the amount of closed cells inside foam from 93.2 to $94.5 \%$, while further increasing of biopolyol share led to deterioration of foam's cellular structure and decrease of closed cell content to $88.2 \%$. Similar effects related to the application of crude glycerol-based polyol were observed in other work [27].

Changes in the closed cell content, as well as in the size of the pores, caused by substitution of petrochemical polyol with CG biopolyol, resulted in noticeable changes in thermal insulation properties of prepared rigid PIR foams. Incorporation of 17.5 and $35 \mathrm{wt} \%$ of biopolyol reduced $\lambda$ value from 25.2 to 22.6 and $22.2 \mathrm{~mW} /(\mathrm{m} \mathrm{K})$, respectively, which can be associated with the reduction of average cell size and slight increase 


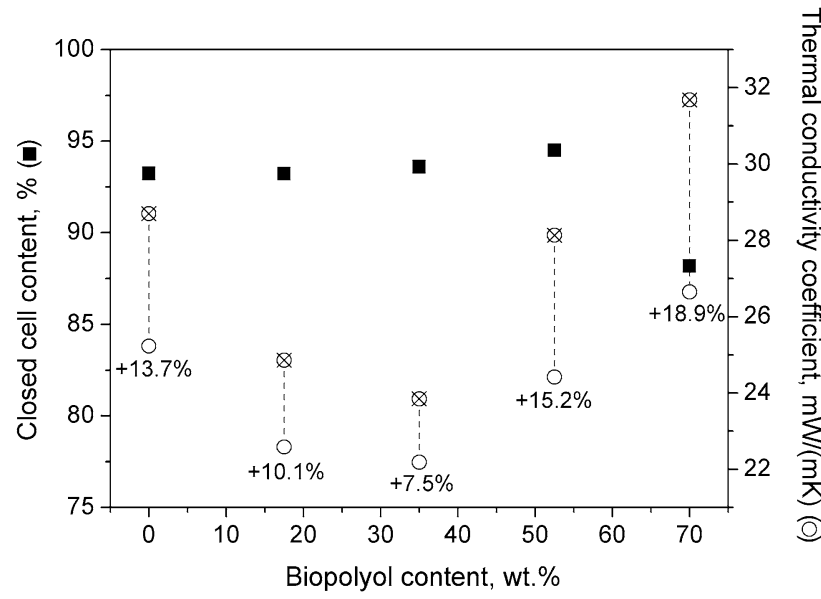

Fig. 9 Values of closed cell content and thermal conductivity coefficients of rigid PIR foams

of closed cell content. Addition of $52.5 \mathrm{wt} \%$ of biopolyol led to slight increase of thermal conductivity coefficient comparing to lower shares, however foam 52.5CG showed better insulation properties than reference sample, with $\lambda$ value of $24.4 \mathrm{~mW} /(\mathrm{m} \mathrm{K})$. Significant deterioration of thermal conductivity in case of 70CG sample is obviously related to the disruption of cellular structure and decreased content of closed cells inside foam. As a result, during measurement, share of air in the gaseous mixture filling the pores is higher than in foams with lower content of biopolyol. As mentioned before $\lambda$ value of used physical foaming agent is almost 2.5 times lower than $\lambda$ value of air.

Very important, from the application point of view is stability of thermal insulation properties of rigid PIR foams, which is related to the changes in thermal conductivity coefficient of foam over time. Such changes are associated with the fact that gases strive to achieve equilibrium between concentration inside and outside of the foam, hence diffusion of gases occurs between the material and surrounding atmosphere. Blowing agents used during manufacturing of foam are escaping from cells, while atmospheric gases are penetrating the foam. Differences in $\lambda$ value between these gases are leading to deterioration of insulation properties. According to Graham's law of effusion, transport of gases through the porous material is strictly correlated with their molecular weight according to the formula (8):

$\frac{\text { rate }_{1}}{\text { rate }_{2}}=\sqrt{\frac{M_{2}}{M_{1}}}$

where rate is the rate of gas effusion; $M$ is molecular weight and subscripts 1 and 2 are describing two gases, which are compared by equation.
According to this formula, effusion of water, nitrogen and oxygen occurs $2.89,2.31$ and 2.17 , respectively, times faster than blowing agent used during foam's manufacturing. Values of $\lambda$ for these gases are around 18, 24 and $24 \mathrm{~mW} /(\mathrm{m} \mathrm{K})$, respectively. It means that penetration of atmospheric gases inside the foam has stronger effect on thermal aging than escaping of blowing agent. However these assumptions, based on Graham's law are true only for porous material and it is important to remember that investigated rigid PIR foams have high content of closed cells, which as it can be seen in the Fig. 9 exceeds 90\% (except 70CG). As a result, Fick's law should be more appropriate to describe the diffusion of gases during thermal aging of foam [53], according to the Eq. (9):

$\frac{\partial \varphi}{\partial t}=D \frac{\partial^{2} \varphi}{\partial x^{2}}$

where $\phi$ is the concentration; $t$ is time and $D$ is the diffusion coefficient.

According to Singh et al. [53], value of the diffusion coefficient of cyclopentane in PIR rigid insulation boards is from 30 to even 100 times lower in comparison to air, thus also water vapor, depending on the manufacturer of foam. It can be assumed that $D$ values for other physical blowing agents are in the same order of magnitude, which strongly indicates that the main factor affecting thermal conductivity coefficient over time is the amount of water vapor surrounding foam.

Murphy [54] investigated thermal aging of rigid PIR foams depending on the storage conditions. Foams were stored at $25{ }^{\circ} \mathrm{C}$ in desiccator, at $25{ }^{\circ} \mathrm{C}$ and relative humidity of $50 \%$, and at $70{ }^{\circ} \mathrm{C}$ and relative humidity of $95 \%$. Thermal conductivity coefficient increased by around 6,8 and $15 \%$, respectively, after 7 days and 6,11 and $22 \%$ after 14 days of storage. These results confirm that humidity of foam's surrounding has crucial impact on its thermal aging.

In the Fig. 9 there are presented values of thermal conductivity coefficients of analyzed foams 1 and 8 days after their manufacturing. Noticeable increase of $\lambda$ value was observed for all investigated materials, however the lowest increase was noted for sample 35CG. Such deterioration of insulation properties can be related to the storage conditions of foams, especially to relative humidity of the environment, which was around $80 \%$. In the light of above mentioned studies, it can be stated that deterioration of insulation properties of investigated foams could be noticeably slowed down by improving storage conditions. Detailed influence of the storage conditions on the thermal insulation properties of crude glycerol-based PIR foams would be topic of further studies.

Thermal degradation of PU materials is very complex process, due to the complexity of their structure. In 
Table 7 Characteristics of thermal degradation of rigid PIR foams

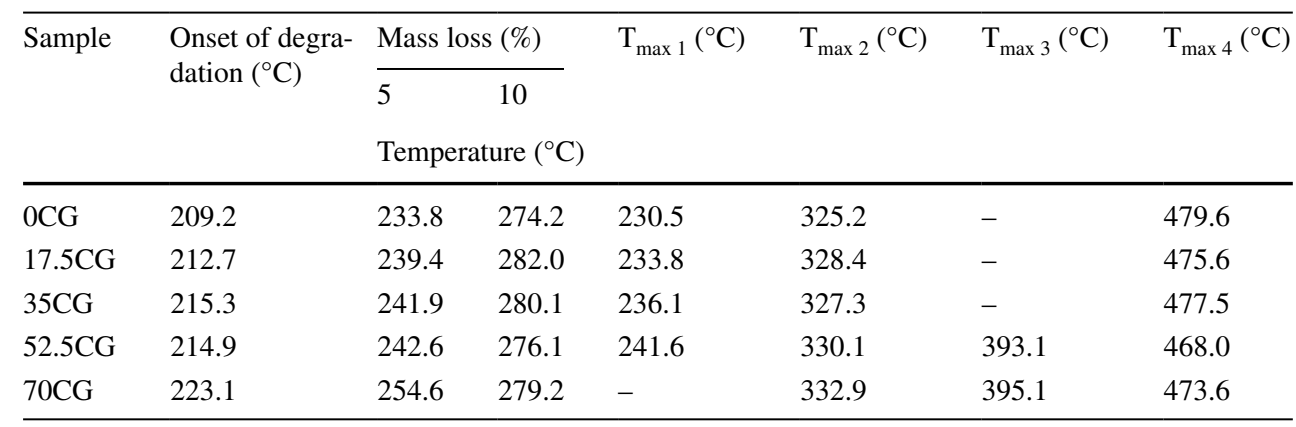

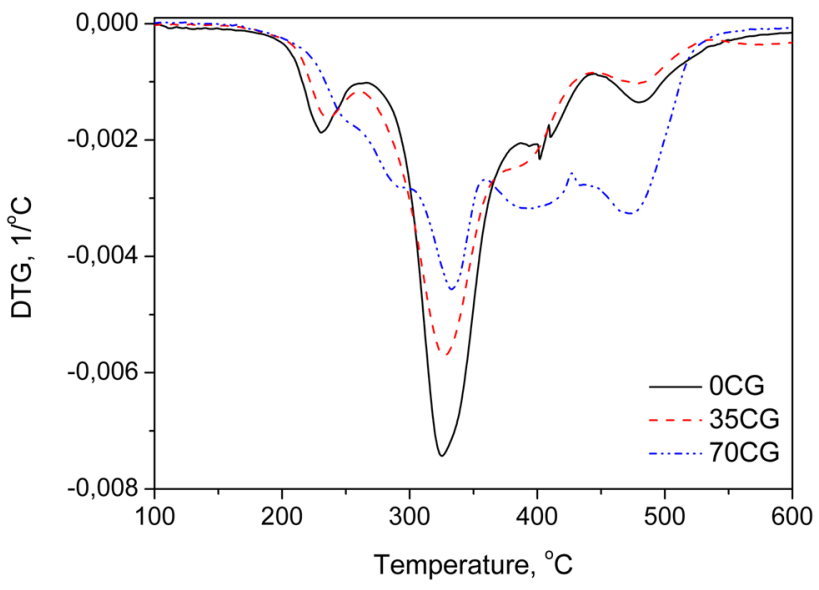

Fig. 11 Differential thermogravimetric curves of rigid PIR foams

and urethane bonds, followed by thermal decomposition leading to the formation of amines, small transition components and carbon dioxide [57, 58]. In case of foams with lower content of CG biopolyol, peak at DTG curve characteristic for rigid segments degradation $\left(T_{\max 2}\right)$ is overlapping with the peak responsible for thermal decomposition of soft segments comprised from Lupranol 3300 (around $350{ }^{\circ} \mathrm{C}$ ). For samples 52.5CG and 70CG, peak related to degradation of soft segments containing of $\mathrm{CG}$ polyol chains was noted around $395{ }^{\circ} \mathrm{C}\left(\mathrm{T}_{\max } 3\right)$. It can be clearly seen that pathway of soft segments' decomposition depends on the structure of used polyols. Moreover, this step is relatively slower than the first one [59, 60]. Finally, around $475{ }^{\circ} \mathrm{C}\left(\mathrm{T}_{\max 4}\right)$ thermolysis of the organic residues from previous steps occurred [61]. It can be seen that the increase of biopolyol share in polyol mixture resulted in shift of DTG peaks towards higher temperatures, which can be associated with the enhanced thermal stability of foams.

Important property of rigid PIR foams used as thermal insulation is their flammability, which directly affects the safety of their use in construction industry. In order to investigate the fire performance of crude glycerol-based foams they were examined using cone calorimeter. Such measurements are one of the most important methods of $\left(\mathrm{T}_{\max 2}\right)$, which involves dissociation of biuret, allophanate 
assessing the fire behavior of materials by allowing determination of various parameters characterizing combustion of material, such as heat release rate (HRR), amount of released heat and smoke, yield of gases generated during combustion and others. In cone calorimetry, analyzed samples are subjected to heat irradiation, which should have intensity at the similar level as experienced in fire situation, in the range of 25 to $75 \mathrm{~kW} / \mathrm{m}^{2}$ [62]. Results of performed analysis are presented in Table 8 and Fig. 12.

As mentioned above, flammability is very important feature of rigid PIR foams used as thermal insulation material. The most important, measurable, single parameter describing the safety of the use of any material is its HRR [63]. Many fire hazard variables are correlated with the HRR, which can be considered as the engine driving the fire. It directly affects the speed of fire spread and thus the size of fire, mass loss rate, amount of toxic gases generated during fire and others. Plots of HRR over time are directly related to the type of material. In the Fig. 12 it can be observed that investigated foams belong to the group of thick charring materials. For such materials, initial increase of heat release rate is observed, until efficient char layer is formed, which noticeably inhibits the fire spread. Further peaks on the HRR curves are associated with the crack formation in char layer and resulting diffusion of oxygen inside the sample [64]. According to Qian et al. [65], unmodified rigid PIR foams used as thermal insulation materials show value of HRR above $300 \mathrm{~kW} / \mathrm{m}^{2}$, while for all analyzed samples did not exceed $190 \mathrm{~kW} / \mathrm{m}^{2}$. Moreover, it can be seen that content of CG biopolyol did not have straightforward impact on the peak height, values of pHRR are maintained at almost the same level, only for 70CG sample decrease was observed. It means that char layer formation on the surface of burning foam was fairly quick.

Furthermore, incorporation up to $35 \mathrm{wt} \%$ of crude glycerol-based biopolyol into rigid foams did not change

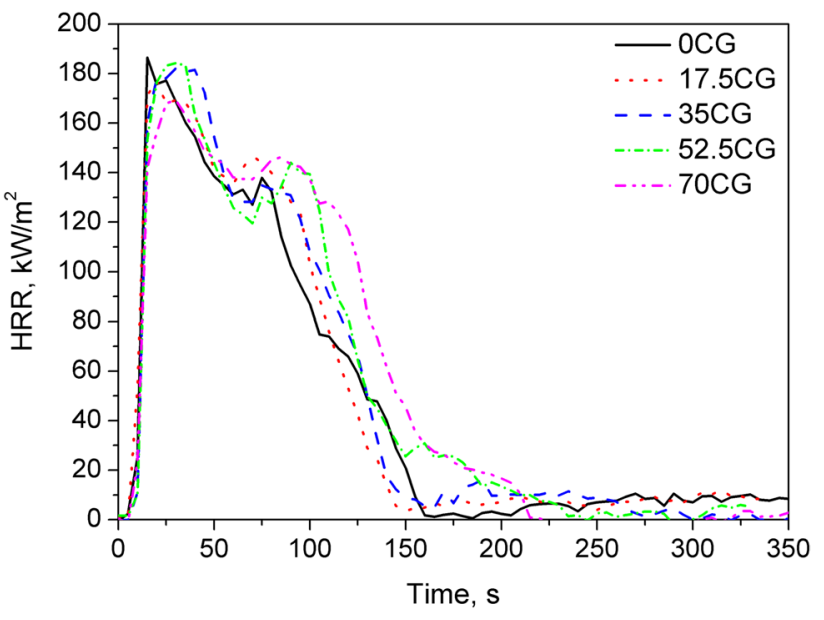

Fig. 12 Plots of HRR for prepared PIR foams

HRR plots. In case of higher shares second peak on HRR curve, resulting from crack formation, was higher and broader, which elongated burning time and increased the total heat release value (THR). As a result of elongated combustion, total smoke release (TSR) value was also increased for samples 52.5CG and 70CG, while for foams with lower content of CG biopolyol TSR was maintained at similar level, when considering standard deviation.

Moreover, it can be seen that incorporation of crude glycerol-based biopolyol resulted in the reduction of carbon dioxide and carbon monoxide emission. Latter compound, generated during incomplete combustion of PIR foam is considered toxic, hence its limited emission can be considered very beneficial from the environmental point of view.

Summarizing cone calorimetry results, foams containing up to $35 \mathrm{wt} \%$ of CG biopolyol show similar fire performance as reference sample, only higher contents resulted in unfavorable changes in combustion pathway.

Table 8 Parameters describing flammability of prepared rigid PIR foams

\begin{tabular}{lllllll}
\hline Sample & $\mathrm{pHRR}^{\mathrm{a}}\left(\mathrm{kW} / \mathrm{m}^{2}\right)$ & $\mathrm{THR}^{\mathrm{b}}\left(\mathrm{MJ} / \mathrm{m}^{2}\right)$ & $\mathrm{TSR}^{\mathrm{c}}\left(\mathrm{m}^{2} / \mathrm{m}^{2}\right)$ & $\mathrm{COY}_{\mathrm{av}}^{\mathrm{d}}(\mathrm{kg} / \mathrm{kg})$ & $\mathrm{CO}_{2} \mathrm{Y}_{\mathrm{av}}^{\mathrm{e}}(\mathrm{kg} / \mathrm{kg})$ & $\mathrm{Char}$ residue $(\mathrm{wt} \%)$ \\
\hline $0 \mathrm{CG}$ & $181.2 \pm 7.5$ & $16.7 \pm 0.3$ & $772 \pm 15$ & $0.2 \pm 0.0$ & $3.0 \pm 0.3$ & $10.6 \pm 1.1$ \\
$17.5 \mathrm{CG}$ & $179.7 \pm 3.2$ & $16.8 \pm 0.1$ & $791 \pm 13$ & $0.2 \pm 0.0$ & $2.9 \pm 0.1$ & $12.6 \pm 2.0$ \\
$35 \mathrm{CG}$ & $182.8 \pm 0.8$ & $16.8 \pm 0.8$ & $798 \pm 52$ & $0.2 \pm 0.0$ & $2.8 \pm 0.0$ & $13.8 \pm 3.9$ \\
$52.5 \mathrm{CG}$ & $183.6 \pm 1.0$ & $19.1 \pm 1.2$ & $972 \pm 14$ & $0.1 \pm 0.0$ & $2.6 \pm 0.1$ & $14.7 \pm 1.4$ \\
$70 \mathrm{CG}$ & $171.5 \pm 3.8$ & $19.7 \pm 0.3$ & $1078 \pm 18$ & $0.1 \pm 0.0$ & $2.5 \pm 0.2$ & $15.1 \pm 0.9$ \\
\hline
\end{tabular}

${ }^{\text {a}}$ Peak heat release rate

${ }^{\mathrm{b}}$ Total heat release

${ }^{\mathrm{c}}$ Total smoke release

${ }^{\mathrm{d}}$ Average yield of carbon oxide

${ }^{\mathrm{e}}$ Average yield of carbon dioxide 


\section{Conclusions}

Rigid PIR foams were prepared by partial substitution (0-70 wt $\%)$ of commercially available petrochemical polyol, with previously synthesized biopolyol based on crude glycerol. Formulations of foams were adjusted to provide similar apparent density of analyzed materials. Incorporation of $70 \mathrm{wt} \%$ of biopolyol decreased amount of hydrofluorocarbon blowing agent used in foams' manufacturing by more than $50 \%$, which can be considered beneficial from the economic and technological point of view. Incorporation of CG biopolyol showed beneficial influence on the morphology of analyzed foams. Up to $52.5 \mathrm{wt} \%$ content of biopolyol, average cell size was reduced by over $30 \%$ and closed cell content was slightly increasing, which resulted in the decrease of thermal conductivity coefficient from 25.2 to $24.4 \mathrm{~mW} / \mathrm{m} \mathrm{K}$. The best thermal insulation performance $(\lambda=22.2 \mathrm{~mW} / \mathrm{m} \mathrm{K})$ and the best resistance for thermal aging was shown by foam containing $35 \mathrm{wt} \%$ of bio-based polyol. Moreover, for increasing biopolyol share, elongation of cells in rise direction was observed, due to the increased heat generation associated with increased crosslink density. Changes in cellular structure and crosslink density were correlated with the results of compression tests. With increasing share of CG biopolyol, compressive strength and stiffness of foams were enhanced. Materials containing $70 \mathrm{wt} \%$ of biopolyol showed compressive strength increased by $121 \%$, while the modulus was increased by $170 \%$. Incorporation of crude glycerol-based polyol resulted in increase of the temperature (by $\sim 14{ }^{\circ} \mathrm{C}$ for $70 \mathrm{wt} \%$ content) related to the onset of thermal degradation and in shift of DTG peaks towards higher temperatures. Increasing share of CG polyol up to $35 \mathrm{wt} \%$ did not lead to noticeable changes in combustion pathway, which can be considered beneficial for the human safety, since values of pHRR, THR, TSR and yield of toxic carbon monoxide were maintained at the same level. Only higher contents of biopolyol resulted in unfavorable changes in combustion pathway.

Summarizing, this work confirms that crude glycerol, as by-product of biodiesel production, can be successfully applied in production of biopolyols for PIR foams, which can be low-cost alternative for conventional, petroleumbased polyols. It can be considered very beneficial from the ecological and economical point of view, due to the utilization of low-cost waste material from renewable raw materials processing. Moreover, obtained results and present state-of-the-art indicate that further studies on that field should focus on: (i) evaluation of the impact of crude glycerol impurities on manufacturing and properties of rigid PIR foams; (ii) examination of aging of crude glycerolbased rigid PIR foams; (iii) evaluation of influence of the storage conditions on the thermal insulation properties of crude glycerol-based PIR foams; (iv) reduction of flammability of crude glycerol-based PIR foams, with environmentally friendly flame retardants.

Open Access This article is distributed under the terms of the Creative Commons Attribution 4.0 International License (http:// creativecommons.org/licenses/by/4.0/), which permits unrestricted use, distribution, and reproduction in any medium, provided you give appropriate credit to the original author(s) and the source, provide a link to the Creative Commons license, and indicate if changes were made.

\section{References}

1. Hoekman SK, Broch A, Robbins C, Ceniceros E (2012) Renew Sust Energ Rev 16:143

2. Petrović Z (2008) Polym Rev 48:109

3. Kurańska M, Prociak A, Kirpluks M, Cabulis U (2015) Ind Crop Prod 74:849

4. Kurańska M, Prociak A (2016) Ind Crop Prod 89:182

5. Zlatanić A, Lava C, Zhang W, Petrović ZS (2004) J Polym Sci B 42:809

6. Chuayjuljit S, Sangpakdee T, Saravari O (2007) J Met Mater Miner 17:17

7. Campanella A, Bonnaillie LM, Wool RP (2009) J Appl Polym Sci 112:2567

8. Fan H, Tekeei A, Suppes GJ, Hsieh FH (2013) J Appl Polym Sci 127:1623

9. Calvo-Correas T, Mosiewicki MA, Corcuera MA, Eceiza A, Aranguren MI (2015) J Renew Mater 3:3

10. Palanisamy A, Karuna MSL, Satyavani T, Rohini Kumar DB (2011) J Am Oil Chem Soc 88:541

11. Silva VR, Mosiewicki MA, Yoshida MI, Silva MC, Stefani PM, Marcovich NE (2013) Polym Test 32:665

12. Yang LT, Zhao CS, Dai CL, Fu LY, Lin SQ (2012) J Polym Environ 20:230

13. Tu YC, Fan H, Suppes GJ, Hsieh FH (2009) J Appl Polym Sci 114:2577

14. Guo A, Demydov D, Zhang W, Petrovic ZS (2002) J Polym Environ 10:49

15. Tran P, Graiver D, Narayan R (2005) J Am Oil Chem Soc 82:653

16. Desai SD, Patel JV, Sinha VK (2003) Int J Adhes Adhes 23:393

17. Puri M, Abraham RE, Barrow CJ (2012) Renew Sust Energ Rev $16: 6022$

18. Ragauskas AJ, Williams CK, Davison BH, Britovsek G, Cairney J, Eckert CA, Frederick WJ Jr, Hallett JP, Leak DJ, Liotta CL, Mielenz JR, Murphy R, Templer R, Tschaplinski T (2006) Science 311:484

19. Fan X, Burton R (2009) Open Fuels Energy Sci J 2:100

20. Nik Siti MNMD, Idris Z, Shoot KY, Hassan HA (2013) J Oil Palm Res 25:289

21. Cheng D, Wang L, Shahbazi A, Xiu S, Zhang B (2014) Fuel 130:251

22. Hu S, Li Y (2014) Ind Crop Prod 57:188

23. Ionescu M, Petrovic ZS (2010) J Cell Plast 46:223

24. Luo X, Hu S, Zhang X, Li Y (2013) Bioresour Technol 139:323

25. Li C, Luo X, Li T, Tong X, Li Y (2014) Polymer 55:6529

26. Piszczyk $€$, Strankowski M, Danowska M, Hejna A, Haponiuk JT (2014) Eur Polym J 57:143

27. European Comission (2017) Thermal insulation-green public procurement product sheet. Accessed 25 June $2017 \mathrm{http} / /$ ec.europa.eu/environment/gpp/pdf/thermal_insulation_GPP_ product_sheet.pdf. 
28. Piszczyk Ł, Danowska M, Haponiuk J, Strankowski M (2014) Polish patent application P.408610

29. Andersons J, Kirpluks M, Stiebra L, Cabulis U (2015) Theor Appl Fract Mech 78:8

30. Kirpluks M, Cabilis U, Zeltins V, Stiebra L, Avots A (2014) Autex Res J 14:259

31. Miyata A, Tsutsui T, Konga N, Matsumoto S, Ohkubo K (2012) Patent EP2080778

32. Wirpsza Z, Banasiak S (2012) Patent PL 210779

33. Hejna A, Kirpluks M, Kosmela P, Cabulis U, Haponiuk J, Piszczyk Ł (2017) Ind Crop Prod 95:113

34. Zieleniewska M, Leszczyński MK, Kurańska M, Prociak A, Szczepkowski L, Krzyżowska M, Ryszkowska J (2015) Ind Crop Prod 74:887

35. Sormana JL, Meredith JC (2004) Macromolecules 37:2186

36. Fournier D, Du Prez F (2008) Macromolecules 41:4622

37. Jiao L, Xiao H, Wang Q, Sun J (2013) Polym Degrad Stabil 98:2687

38. Samborska-Skowron R, Balas A (2003) Polimery 48:371

39. Pretsch T, Jakob I, Müller W (2009) Polym Degrad Stabil 94:61

40. Mosiewicki MA, Dell'Arciprete GA, Aranguren MI, Marcovich MA (2009) J Compos Mater 43:3057

41. Modesti M, Lorenzetti A (2003) Eur Polym J 39:263

42. Kong X, Yue J, Narine SS (2007) Biomacromolecules 8:3584

43. Guo H, Gao Q, Ouyang C, Zheng K, Xu W (2015) J Appl Polym Sci 132:42349

44. Bagdi K, Molnar K, Sajo I, Pukanszky B (2011) Express Polym Lett 5:417

45. Narine SS, Kong X, Bouzidi L, Sporns P (2007) J Amer Oil Chem Soc 84:65

46. Tan S, Abraham T, Ference D, Macosko CW (2011) Polymer 52:2840

47. Bindu P, Thomas S (2013) J Phys Chem B 117:12632

48. Javni I, Zhang W, Petrović ZS (2004) J Polym Environ 12:123
49. Szycher M (1999) Szycher's handbook of polyurethanes, 1st edn. CRC Press, Boca Raton

50. Randall D, Lee S (2002) The polyurethanes book. Wiley, New York

51. Glicksman LR (1994) Heat transfer in foams. In: Hylyard NC, Cunningham A (eds) Low density cellular plastics. Kluwer Academic Publishers, Dordrecht, pp 115-116t;/bib>

52. Bogdan M, Hoerter J, Moore FO (2005) J Cell Plast 41:41

53. Singh S, Ntiru M, Dedecker K (2002) Long term thermal resistance of pentane blown polyisocyanurate laminate boards. In: API proceedings, Salt Lake City, pp 19-26

54. Murphy J (2010) Long term aging of closed-celled foam insulation. In: Proceedings of polyurethane technical conference, Houston, p 320

55. Wrześniewiska-Tosik K, Zajchowski S, Bryśkiewicz A, Ryszkowska J (2014) Fibres Text East Eur 22:119

56. Septevani AA, Evans DAC, Chaleat C, Martin DJ, Annamalai PK (2015) Ind Crop Prod 66:16

57. Somania KP, Kansaraa SS, Patelb NK, Rakshit AK (2003) Int J Adhes Adhes 23:269

58. Tanaka R, Hirose S, Hatakeyama H (2008) Bioresource Technol 99:3810

59. Cervantes-Uc JM, Moo Espinosa JI, Cauich-Rodriguez JV, Avila-Ortega A, Vazquez-Torres H, Marcos-Fernandez A, San Roman J (2009) Polym Degrad Stab 94:1666

60. Pawlik H, Prociak A (2012) J Polym Environ 20:438

61. Zhang L, Zhang M, Zhou Y, Hu L (2013) Polym Degrad Stab 98:2784

62. Berta M, Lindsay C, Pans G, Camino G (2006) Polym Degrad Stab 91:1179

63. Babrauskas V, Peacock RD (1992) Fire Saf J 18:255

64. Schartel B, Hull TR (2007) Fire Mater 31:327

65. Qian L, Feng F, Tang S (2014) Polymer 55:95 